\title{
Acetate-Free Biofiltration Reduces Intradialytic Hypotension: A European Multicenter Randomized Controlled Trial
}

\author{
Nicola Tessitore ${ }^{a}$ Antonio Santoro ${ }^{c}$ Giovanni Oliviero Panzetta ${ }^{d}$ \\ Volker Wizemann ${ }^{\mathrm{e}}$ Rafael Perez-Garcia ${ }^{\mathrm{f}}$ Jorge Martinez Ara ${ }^{\mathrm{g}}$ Bruno Perrone ${ }^{\mathrm{h}}$ \\ William Mantovani ${ }^{b}$ Albino Polib \\ ${ }^{a}$ Division of Nephrology and ${ }^{\mathrm{b}}$ Department of Public Health, Azienda Ospedaliera Universitaria Integrata-Verona, \\ Verona, ' Nephrology, Dialysis and Hypertension Department, University of Bologna and S. Orsola-Malpighi Hospital, \\ Bologna, and ${ }^{\mathrm{d}}$ Nephrology and Dialysis Complex Structure, Trieste, Italy; ${ }^{\mathrm{e}}$ Georg-Haas Dialysezentrum, Giessen,

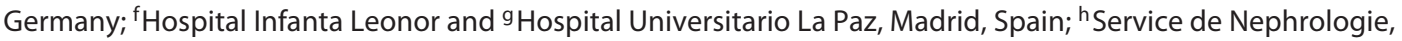 \\ Centre Hospitalier de Saintonge, Saintes, France
}

\section{Key Words}

Bicarbonate hemodialysis · Acetate-free biofiltration . Hemodiafiltration · Intradialytic hypotension · Systolic blood pressure · Cardiovascular morbidity · Cardiovascular mortality

\footnotetext{
Abstract

Background: Intradialytic hypotension $(\mathrm{IH})$ is a common complication of bicarbonate hemodialysis (BD) and contributes to the intolerance of dialysis and the high cardiovascular morbidity and mortality among dialysis patients, the risk of which can be contained by convective therapies. Aims/ Methods: To assess whether acetate-free biofiltration (AFB), a hemodiafiltration technique found to improve intradialytic cardiovascular stability in short-term studies, can influence long-term IH rates, predialysis systolic blood pressure (SBP), cardiovascular morbidity and mortality by comparison with $\mathrm{BD}$, we analyzed data from a randomized controlled trial enrolling 371 new-to-dialysis patients, 194 on BD and 177 on AFB. Results: During a 3-year follow-up, AFB carried a significantly lower risk of $\mathrm{IH}$ (incidence rate ratio $0.60(95 \% \mathrm{Cl}$
}

0.53-0.68), $p<0.0001)$. SBP dropped on AFB $(p=0.01)$, while it did not change on BD. Cardiovascular morbidity and mortality were similar between AFB and BD. Conclusion: AFB carries a lower long-term IH rate and reduces SBP by comparison with $\mathrm{BD}$.

Copyright $\odot 2013$ S. Karger AG, Basel

\section{Introduction}

Various factors make hemodialysis (HD) patients sensitive to cardiovascular events and death [1-9]. Conventional short, intermittent HD treatments themselves may contribute to the high rate of cardiac events in HD patients as a result of intradialytic hypotension (IH) [10], the most frequent complication of the standard HD procedure [11], which not only contributes to reducing the tolerability of dialysis but also causes a drop in coronary blood flow, which would lead to a left ventricular dysfunction that may persist even after a return to normal perfusion (myocardial stunning) $[12,13]$. Such repeated, $\mathrm{HD}$-induced ischemic events may raise the mortality rate 
[14-17], cause sudden death [18], and have a role in the onset of heart failure $[3,19]$ and inability to reach the required dry weight, leading to fluid overload and its untoward effects, hypertension and left ventricular hypertrophy [20]. The HD procedure may also carry the risk of a reduced perfusion to other vascular beds in vulnerable organ systems [21, 22], such as the brain, and therefore contribute to the higher risk of cerebrovascular events in dialysis patients [23].

Modified dialysis procedures (such as biofeedbackcontrolled and cooled dialysis, or online hemofiltration and hemodiafiltration) has been shown to improve the hemodynamic tolerability of dialysis and to reduce the risk of $\mathrm{IH}[24,25]$, resulting in a lower likelihood of cardiac injury $[26,27]$. Another strategy for containing the risk of IH may be acetate-free biofiltration (AFB), a lowvolume hemodiafiltration technique based on buffer-free dialysate, a biocompatible high-flux membrane, and sterile bicarbonate infusion in postdilution mode [28], which has been shown to improve systemic hemodynamics during dialysis in short-term studies [29], although this remains controversial [30].

To establish whether AFB improves long-term cardiovascular stability during dialysis, we analyzed the data collected in the open controlled randomized European multicenter study on the morbidity and mortality relating to AFB and bicarbonate hemodialysis (BD) [31], which had $\mathrm{IH}$ as the preset endpoint and enrolled patients at high risk of dialysis-related adverse events because they were elderly, diabetic and/or hypotension-prone on BD. Secondary aims of the study were to evaluate the influence of AFB on blood pressure, left ventricular mass index (LVMI), and cardiovascular morbidity and mortality, as compared with BD.

\section{Methods}

\section{Study Design}

The design of the trial has been described elsewhere [31]. The trial recruited patients from 92 European HD centers between March 1998 and December 2002 and ended in December 2006. All study procedures complied with the principles of the Helsinki Declaration. The study was approved by the local Ethics Committee of the Malpighi Hospital, Bologna, Italy, and registered under the Current Controlled Trials No. ISRCTN37257308.

Incident HD patients $18-78$ years of age who started on conventional three times weekly $\mathrm{BD}$ were assessed for eligibility at the end of a 6- to 8-month stabilization period to identify their dry weight (on clinical grounds) and ensure the maturity of their vascular access, plus an extra 2-month run-in period to assess their intradialytic cardiovascular stability. Patients were eligible for the study if they were considered 'critical', i.e. at high risk of dialysisrelated adverse cardiovascular events because they were elderly ( $>60$ years of age), diabetic and hypotension-prone (i.e. experiencing IH episodes in $>20 \%$ of the dialysis sessions during the 2 -month run-in period on $\mathrm{BD})$. The exclusion criteria are reported elsewhere [31]. Eligible patients were enrolled after providing their informed consent and were randomly assigned to receive AFB or to continue on BD. Randomization was done centrally (with a computerized random-number generator) using the balanced block randomization technique with a 1:1 ratio, stratification according to the clinical center concerned and a block size of eight. After randomization, baseline Charlson comorbidity index [32], IH rate, pre- and postdialysis blood pressures (averaged over six consecutive dialysis treatments), cardiovascular data (including two-dimensional, M-mode and Doppler echocardiographic evaluation approximately $24 \mathrm{~h}$ after a mid-week dialysis session), dialysis prescription, biochemical data, outpatient medications (including classes of antihypertensive drugs and phosphate binders, nitrates, and antiplatelet agents) were recorded during an additional 2-week period on BD.

Dialysis prescriptions were at the discretion of the attending nephrologists and adjusted so that dialysis machine ultrafiltration control system, dialysate temperature, composition and flow, dialysis time, $\mathrm{Q}_{\mathrm{b}}$, ultrafiltration rate, and target $\mathrm{spKt} / \mathrm{V}>1.2[33]$ were comparable for the two dialysis techniques at a given center. For the BD group, low- or high-flux synthetic membranes and dialysate with bicarbonate and acetate concentrations of 30-34 and 4-6 mM, respectively, were used according to each center practice patterns. AFB was conducted using the AN69 membrane, infusing a 145-167 $\mathrm{mM}$ sodium bicarbonate solution usually warmed to a temperature similar to that of the dialysate, at a rate targeting for a postdialysis plasma bicarbonate levels of 27-30 $\mathrm{mEq} / \mathrm{l}$. Water and dialysate quality were not ultrapure and complied with the criteria specified in the European Pharmacopoeia of 1997.

The study lasted 3 years during which time the number of $\mathrm{IH}$ episodes (occurring over a fortnight) was recorded every 6 months. All IH episodes occurring during each 6-month interval were also recorded. IH was defined as (i) a symptomatic drop of systolic blood pressure (SBP) of at least $25 \mathrm{~mm} \mathrm{Hg}$, requiring nursing intervention (any fluid administration or transient withdrawal of ultrafiltration), or premature termination of the session, (ii) a SBP $<90 \mathrm{~mm} \mathrm{Hg}$ even in the absence of symptoms in patients with predialysis SBP $>100 \mathrm{~mm} \mathrm{Hg}$, or (iii) a symptomatic drop in SBP by at least $10 \%$ of the predialysis value for chronically hypotensive patients with a predialysis SBP $\leq 100 \mathrm{~mm} \mathrm{Hg}$.

In addition, adherence to the protocol, dialysis parameters, pre- and postdialysis body weight and SBP (averaged over six consecutive dialysis treatments), biochemical data, and outpatient medications were assessed every 6 months. LVMI [34] was evaluated every 6 months in the first year of follow-up and then yearly. To identify any carryover effect of the intradialytic events on clinical outcomes, all clinical events (including deaths, hospital admissions and their causes) were collected by the attending nephrologists up to 4 years of follow-up based on the EDTA codes, and were assessed independently by two of the three principal investigators of the study (A.S., G.O.P., N.T.). Dropouts and deaths due to noncardiovascular causes were included in the survival analysis and censored at the time of premature termination. 
Fig. 1. Flow diagram of the Controlled Randomized European Study on Mortality and Morbidity [30].

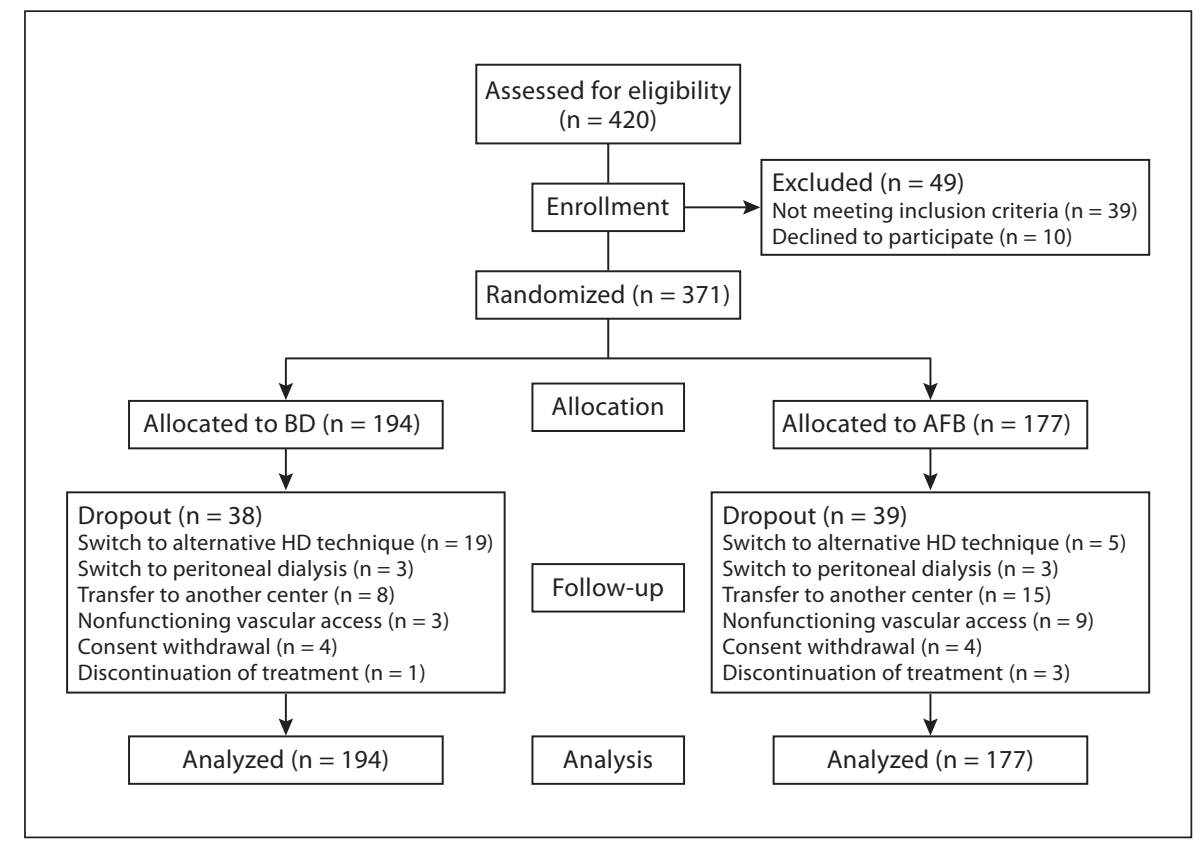

Outcomes

The main outcome was the change in IH rate. Secondary outcomes were changes in predialysis SBP and LVMI, and cardiovascular mortality, morbidity and case fatality rates (i.e. the risk of cardiovascular death after a cardiovascular event). Cardiovascular mortality was defined as death due to cardiac causes (cardiac arrest, acute myocardial infarction or heart failure), or stroke (ischemic or hemorrhagic). A major cardiovascular event (MCE) was defined as a fatal or nonfatal cardiac event (cardiac arrest, heart failure, myocardial infarction, prolonged angina, the need for coronary angioplasty or bypass surgery) or stroke. The early cardiovascular case fatality rate was defined as the percentage of patients with an MCE that proved fatal. The long-term case fatality rate described the number of cardiovascular deaths among patients who had an MCE and survived 28 days or more afterwards [35].

\section{Statistical Analysis}

Data are reported as means $\pm S D, \pm$ SE or $(95 \%$ confidence interval (CI)), medians, percentages and rates, as appropriate. Categorical variables are compared with the $\chi^{2}$ test and continuous variable with Student's t test or the Mann-Whitney U test. Poisson's analysis was used to estimate differences in rates. The relative effect of treatment on $\mathrm{IH}$ rate was assessed by the incidence rate ratio (IRR), derived by the $\mathrm{IH}$ incidence rate (the total number of events divided by the sum of person-years of follow-up) for AFB divided by the $\mathrm{IH}$ incidence rate for $\mathrm{BD}$ [36]. Cardiovascular survival was defined as the time from randomization to cardiovascular death and estimated using the Kaplan-Meyer method. A generalized linear model was used to identify the determinants of the follow-up IH rates, and a Cox's multivariate proportional hazards model to pinpoint predictors of cardiovascular mortality. Differences were considered significant at $\mathrm{p} \leq 0.05$.

\section{Results}

The flow diagram of the Controlled Randomized European Study on Mortality and Morbidity [31] is shown in figure 1 . The median number of participants (range) per center was $2(1-4)$ on BD and $2(1-4)$ on AFB.

Table 1 shows the patients' baseline characteristics. The two groups were well matched, except for the proportion of hypotension-prone patients. Table 2 shows the baseline dialysis prescriptions and ultrafiltration rates.

The proportion of patients dropping out during the follow-up and the reasons for doing so were comparable in the two treatment groups (fig. 1).

\section{Primary Outcome}

Figures 2 and 3 show the baseline and follow-up IH rates and the changes in $\mathrm{IH}$ rates during the follow-up, respectively. The cumulative drop in $\mathrm{IH}$ rate during follow-up was 0.468 (95\% CI 0.088-0.847) episode/patientmonth for BD (from 3.154 (95\% CI 2.936-3.544) at runin to 2.686 (95\% CI $2.529-2.829)$ ) and 2.000 (95\% CI 1.613-2.386) for AFB (from 4.154 (95\% CI 3.717-4.627) to $2.154(95 \%$ CI $2.003-2.313)$ ) ( $\mathrm{p}<0.0001)$. The IH rate for AFB was significantly higher than for BD at run-in, and significantly lower at follow-up $(\mathrm{p}<0.0001)$. The reasons for the unbalanced baseline IH rate are not readily apparent, but this unbalance may be due to the fact that no blinding was used in our study and/or to a more ag- 
Table 1. Patients' baseline characteristics

\begin{tabular}{|c|c|c|c|}
\hline & $\mathrm{BD}(\mathrm{n}=194)$ & $\operatorname{AFB}(n=177)$ & $\mathrm{p}$ \\
\hline Male/female & $112 / 82$ & $106 / 71$ & 0.75 \\
\hline Age, years & $67.1 \pm 8.8$ & $66.9 \pm 8.8$ & 0.88 \\
\hline Proportion of patients aged 65 years or more, $\%$ & 66.0 & 68.4 & 0.88 \\
\hline BMI & $25.2 \pm 4.6$ & $25.0 \pm 4.6$ & 0.71 \\
\hline Vascular access, AVF/PTFE/permanent CVC & $177 / 5 / 12$ & $157 / 8 / 12$ & 0.49 \\
\hline Charlson comorbidity index & $5.9 \pm 1.8$ & $5.9 \pm 1.6$ & 0.9 \\
\hline Diabetes & 41.1 & 37.1 & \\
\hline Ischemic heart disease & 27.6 & 30.6 & \\
\hline Congestive heart failure & 8.9 & 12.2 & \\
\hline Cerebrovascular disease & 16.7 & 17.1 & \\
\hline Peripheral vascular disease & 24.5 & 31.2 & \\
\hline Predialysis SBP, mm Hg & $145.7 \pm 19.2$ & $144.9 \pm 19.1$ & 0.70 \\
\hline
\end{tabular}

${ }^{1}$ Patients with $\geq 20 \%$ dialysis sessions with hypotensive episodes over the 2-month run-in period.

Table 2. Dialysis prescriptions

\begin{tabular}{llll}
\hline & BD $(\mathrm{n}=194)$ & AFB $(\mathrm{n}=177)$ & $\mathrm{p}$ \\
\hline Dialysis time, min & $234 \pm 25$ & $230 \pm 28$ & 0.90 \\
Ultrafiltration rate, $\mathrm{l} /$ session & $2.27 \pm 0.85$ & $2.28 \pm 0.98$ & 0.85 \\
Blood pump flow rate, $\mathrm{ml} / \mathrm{min}$ & $284 \pm 34$ & $290 \pm 35$ & 0.77 \\
Median dialysate sodium, mEq/l & 140 & 140 & 0.94 \\
Infusion rate, $\mathrm{l} / \mathrm{h}$ & - & $2.0 \pm 0.2$ & - \\
Median infusate bicarbonate, mEq/l & - & 145 & - \\
Dialysis membranes, \% & & & \\
$\quad$ AN69 & 14.4 & 100 & \\
$\quad$ Other high-flux & 19.6 & - & \\
$\quad$ Low-flux & 66.0 & - & \\
\hline
\end{tabular}

Table 3. Determinants of IH rate during the follow-up at multivariate analysis

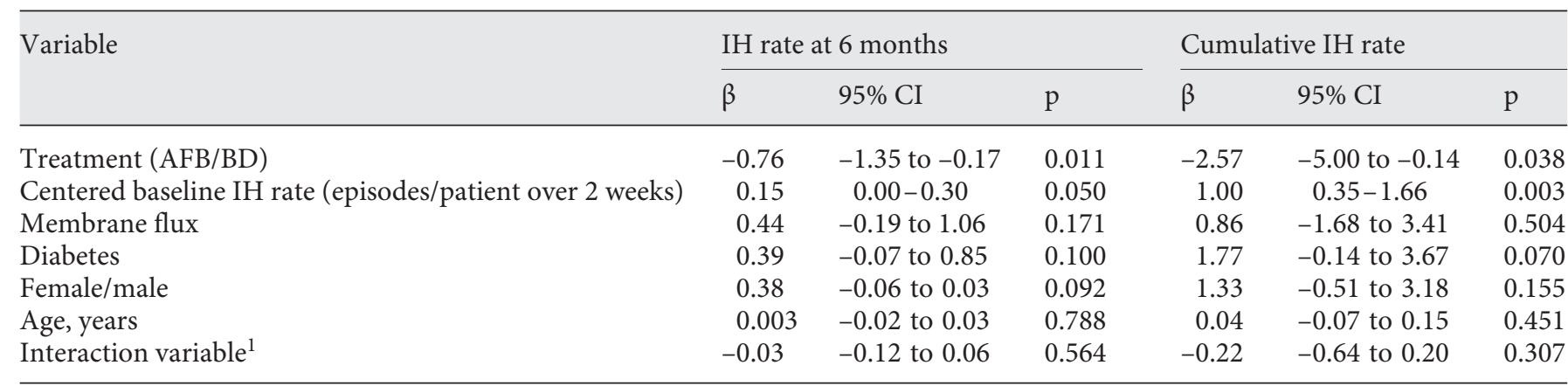

${ }^{1}$ The interaction variable was obtained by combining the centered baseline IH rate and the treatment modality. 


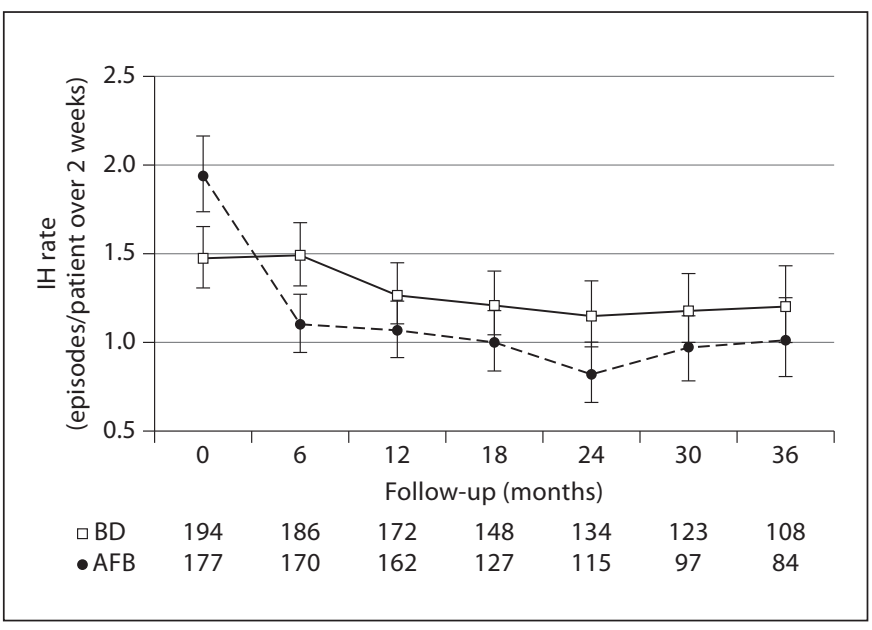

Fig. 2. $\mathrm{IH}$ rate on $\mathrm{BD}$ and $\mathrm{AFB}$ at baseline and during follow-up. Data are expressed as mean $(95 \% \mathrm{CI})$. The IH rate for AFB was significantly higher than for $\mathrm{BD}$ at baseline $(\mathrm{p}=0.0007)$ and significantly lower after 6 and 24 months $(\mathrm{p}<0.01)$.

gressive dehydration before randomization for AFB patients (this hypothesis cannot be tested, however, because no data were available on the changes in dry weight from the initiation of dialysis to randomization). Given the significant difference in the baseline $\mathrm{IH}$ rate between $\mathrm{BD}$ and $A F B$, a test of interaction was performed by centering baseline IH rate [37] and an interaction variable was included in the generalized linear model used to identify the determinants of follow-up IH rate (table 3 ). At multivariate analysis, the only significant, independent determinants of the $\mathrm{IH}$ rate during the follow-up were treatment (AFB being associated with a lower IH rate) and the baseline $\mathrm{IH}$ rate (the higher the baseline, the higher the $\mathrm{IH}$ rate during the follow-up). AFB and baseline IH rate remained the only significant determinants of the IH rate during the follow-up when age and diabetes were substituted by the Charlson comorbidity index, and when the country of origin was added as variable in the model (data not shown). Figure 4 shows the IRR at run-in and follow-up.

There were no significant differences within and between the two groups in terms of baseline and follow-up intradialytic ultrafiltration and dry weight (fig. 5).

\section{Secondary Outcomes}

Figure 6 shows the changes in mean predialysis SBP. The proportion of individuals not requiring antihypertensive therapy during the follow-up increased on AFB (from 34 to $39 \%, \mathrm{p}=0.01$ ) and remained stable on $\mathrm{BD}$ $(35 \%, \mathrm{p}=1.00)$. The mean $(95 \% \mathrm{CI})$ number of antihy-

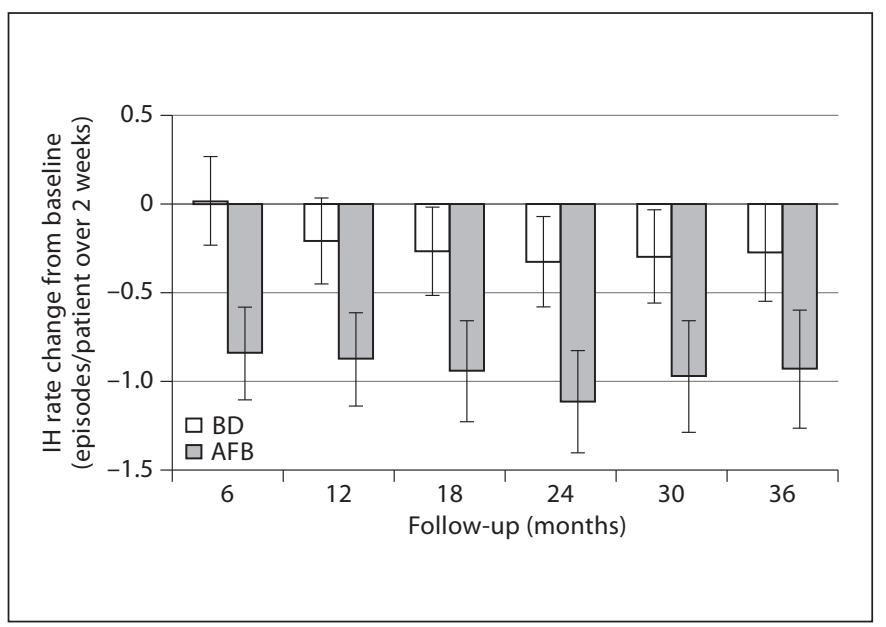

Fig. 3. Drop in $\mathrm{IH}$ rate during follow-up on $\mathrm{BD}$ and AFB. Data are expressed as mean (95\% CI). The drop was significantly higher for AFB than for BD at any given time point $(\mathrm{p}<0.0001)$.

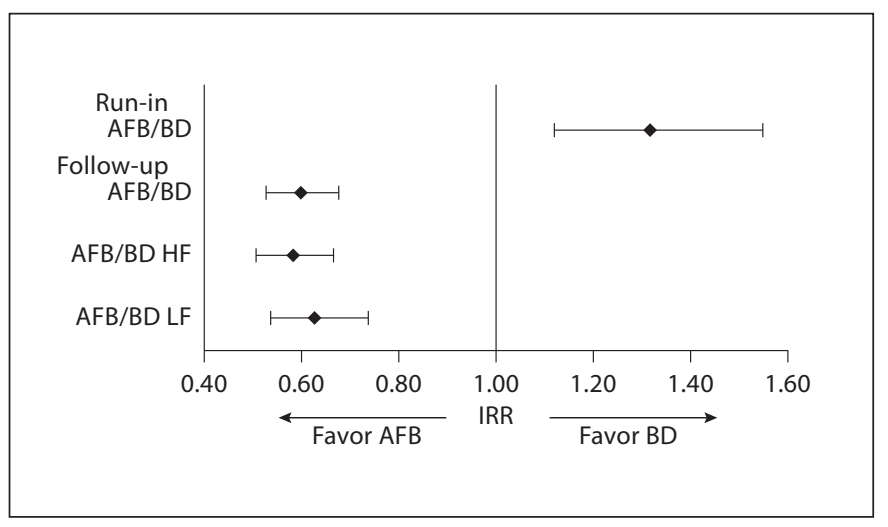

Fig. 4. Unadjusted IH IRR and associated 95\% CIs at run-in and follow-up. The IRR for AFB was significantly higher than for BD at the baseline $(\mathrm{p}<0.0001)$ and significantly lower at the follow-up $(\mathrm{p}<0.0001)$. The same pattern was observed during the follow-up when $\mathrm{AFB}$ was compared with subgroups of $\mathrm{BD}$ patients on highflux (BD HF) $(\mathrm{p}<0.0001)$ and low-flux membranes (BD LF) $(\mathrm{p}=$ $0.0001)$, with no difference between the latter.

pertensives classes did not change significantly in both groups (from 0.889 (0.717-1.061) to 0.954 (0.779-1.129) for $\mathrm{BD}, \mathrm{p}=0.456$, and from $0.992(0.728-1.116)$ to 0.740 (0.576-0.904) for AFB, $p=0.080)$, with no significant differences between groups at baseline $(p=0.092)$ and during the follow-up $(\mathrm{p}=0.070)$. Figure 7 shows the changes in mean LVMI. 

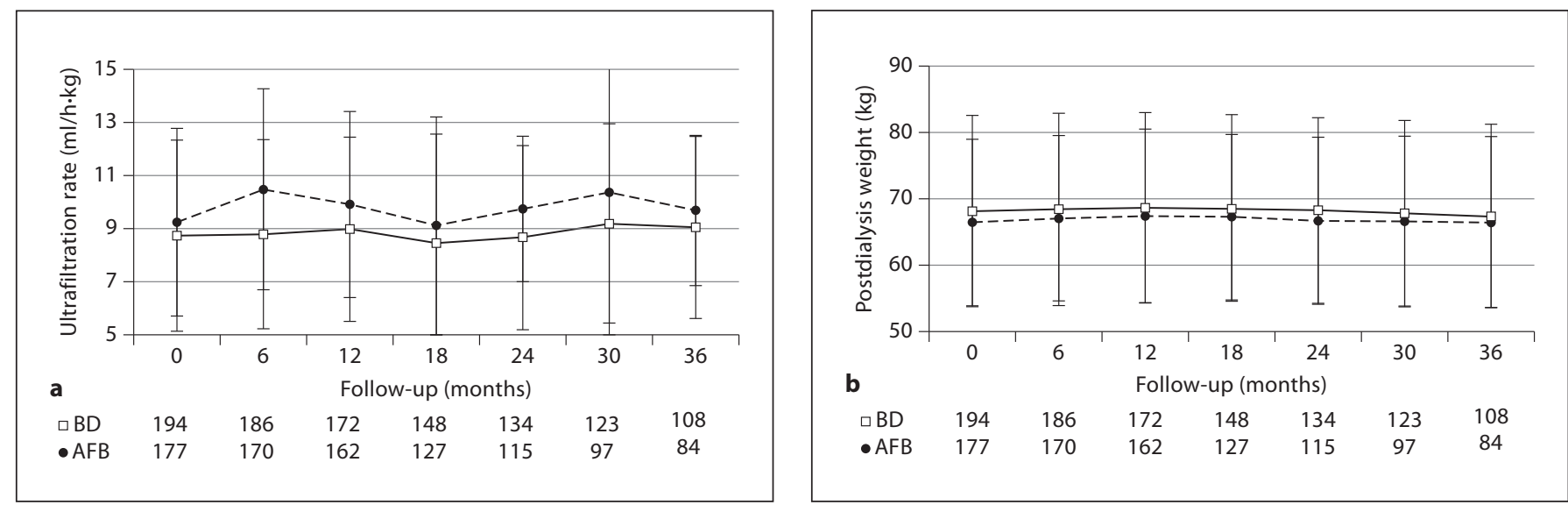

Fig. 5. Mean $(95 \% \mathrm{CI})$ intradialytic ultrafiltration rate $(\mathrm{ml} / \mathrm{h} \cdot \mathrm{kg})(\mathbf{a})$ and dry weight $(\mathrm{kg})(\mathbf{b})$ at the baseline and during follow-up on $\mathrm{BD}$ and AFB. There were no differences within or between groups for either parameter.

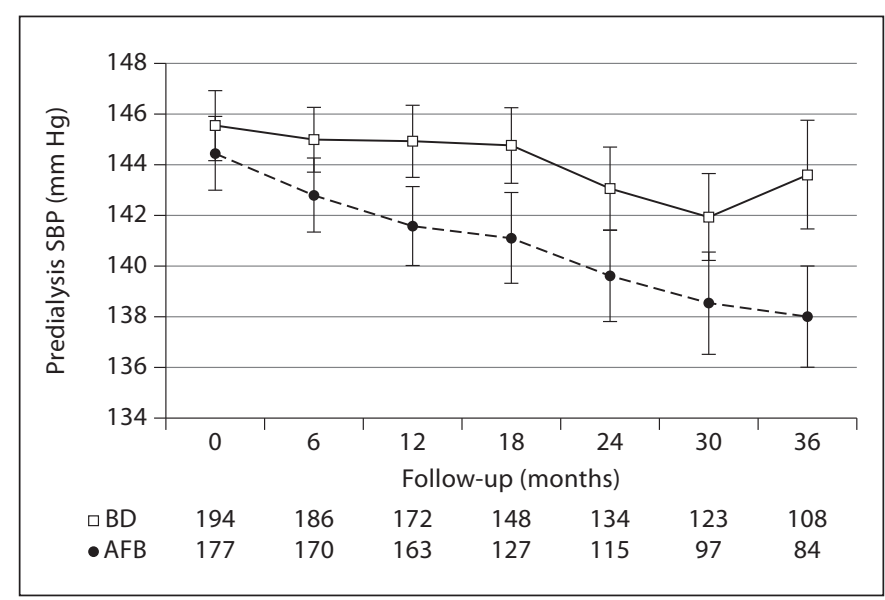

Fig. 6. Mean predialysis SBP values at baseline and during followup on BD and AFB. Mean predialysis SBP did not change in BD patients (from $146+19$ to $144+22 \mathrm{~mm} \mathrm{Hg}, \mathrm{p}=0.13$ for linear trend), while it dropped significantly in AFB patients (from $145+$ 19 to $138+18 \mathrm{~mm} \mathrm{Hg}, \mathrm{p}=0.004$ for linear trend). Predialysis SBP for AFB was significantly lower than for BD after 12,18 , and 36 months $(\mathrm{p}<0.04)$.

84 patients died of cardiovascular causes, 48 on BD (11 myocardial infarctions, 14 heart failures, 11 cardiac arrests, and 12 strokes) and 36 on AFB (7 myocardial infarctions, 9 heart failures, 12 cardiac arrests, and 8 strokes) $(\mathrm{p}=0.31)$. Figure 8 shows the unadjusted cardiovasculardeath-free survival, showing no difference between $\mathrm{BD}$ and AFB patients $(\mathrm{p}=0.56)$.

In the Cox's multivariate analysis (adjusting for gender, country of origin, type of $\mathrm{HD}$, baseline IH rate, Charl-

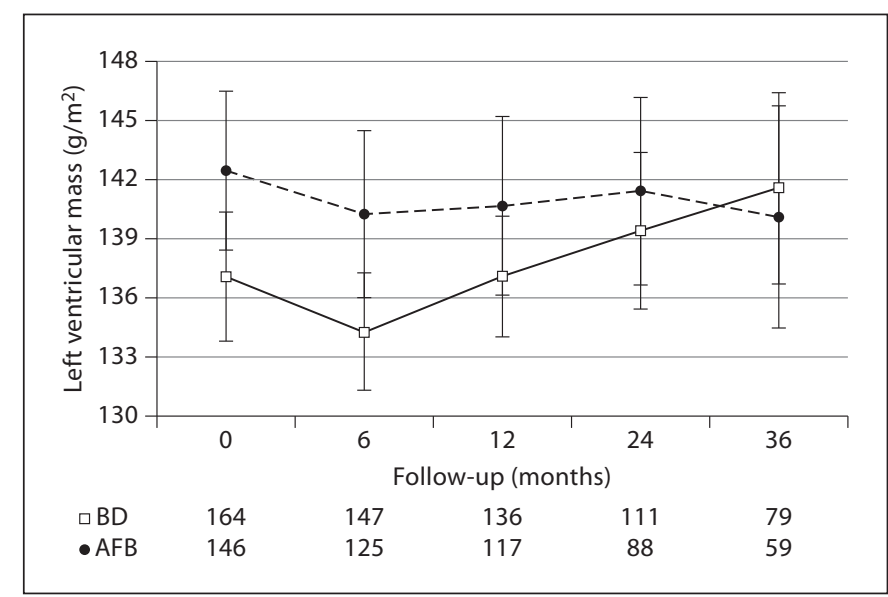

Fig. 7. Mean LVMI values at baseline and during follow-up on BD and AFB. The within- and between-group differences were not significant. Median LVMI tended to increase in cases on BD (4.76 (IQ range -1.15 to 13.26$) \mathrm{g} / \mathrm{m}^{2}$ ), and to decrease in those on AFB $\left(-2.36(\right.$ IQ range -13.92 to 7.44$\left.) \mathrm{g} / \mathrm{m}^{2}\right)(\mathrm{p}=0.14)$.

son comorbidity index, predialysis SBP, LVMI, serum albumin, total cholesterol and phosphate, and spKt/V) the only significant predictor of a higher cardiovascular mortality was the Charlson comorbidity index (HR 1.291 (95\% CI 1.128-1.479), $\mathrm{p}<0.001$ ).

MCEs occurred in 116 patients, $31.4 \%$ on $\mathrm{BD}$ and $31.1 \%$ on AFB ( $p=0.96)$. The proportion of patients who had a fatal MCE (i.e. the early case fatality rate) was similar for the two treatment groups, whereas the long-term 
Table 4. Case fatality rates of MCEs

\begin{tabular}{lllr}
\hline & BD & AFB & RR AFB vs. BD \\
\hline Number of subjects who had MCE & 61 & 55 & - \\
$\quad$ Cardiac events & 38 & 34 & - \\
$\quad$ Stroke & 23 & 21 & \\
Early case fatality rate, \% (n) & $52.5(32 / 61)$ & $52.7(29 / 55)$ & $1.01(0.71-1.43)$ \\
Long-term case fatality rate, \% (n) & $55.2(16 / 29)$ & $26.9(7 / 26)$ & $0.49(0.40-0.99)$ \\
\hline
\end{tabular}

Table 5. Baseline and follow-up predialysis biochemical parameters and dose of dialysis

\begin{tabular}{|c|c|c|c|c|c|c|c|c|c|c|}
\hline & \multicolumn{5}{|c|}{ Baseline } & \multicolumn{5}{|c|}{ Follow-up } \\
\hline & mean & $95 \% \mathrm{CI}$ & mean & $95 \% \mathrm{CI}$ & $\mathrm{p}$ & mean & $95 \% \mathrm{CI}$ & mean & $95 \% \mathrm{CI}$ & $\mathrm{p}$ \\
\hline Hemoglobin, g/dl & 10.7 & $10.4-11.0$ & 10.4 & $10.2-10.6$ & 0.11 & $11.1^{*}$ & $10.9-11.3$ & $11.3^{*}$ & $11.0-11.6$ & 0.72 \\
\hline Albumin, $g / 1$ & 3.88 & $3.80-3.96$ & 3.90 & $3.79-4.00$ & 0.68 & 3.81 & $3.74-3.88$ & 3.80 & $3.72-3.88$ & 0.76 \\
\hline Total cholesterol, mg/dl & 204 & $196-212$ & 198 & $191-205$ & 0.25 & 199 & 190-208 & 194 & $185-203$ & 0.81 \\
\hline Triglyceride, mg/dl & 209 & $192-226$ & 207 & $188-226$ & 0.84 & 194 & $174-214$ & 181 & $162-200$ & 0.39 \\
\hline Bicarbonate, mEq/l & 20.6 & $20.2-21.0$ & 21.1 & $20.7-21.5$ & 0.11 & 20.9 & $20.4-21.4$ & 21.7 & $21.1-22.3$ & 0.11 \\
\hline $\mathrm{spKt} / \mathrm{V}$ & 1.31 & $1.28-1.34$ & 1.32 & $1.28-1.36$ & 0.67 & $1.41^{*}$ & $1.36-1.45$ & $1.46^{\star}$ & $1.41-1.51$ & 0.09 \\
\hline
\end{tabular}

${ }^{*} \mathrm{p}<0.02$ vs. baseline.

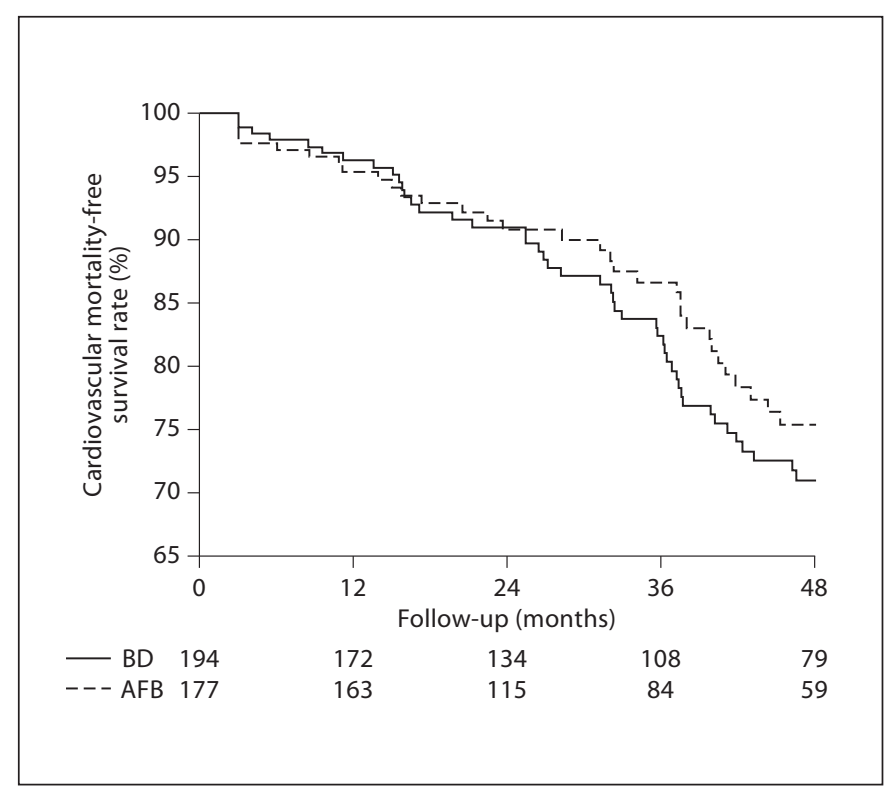

Fig. 8. Unadjusted cardiovascular mortality-free survival rate. Survival was similar in AFB and in BD patients $(\mathrm{p}=0.23)$. case fatality rate (i.e. the proportion of cardiovascular deaths among patients who had an MCE and survived 28 days or more afterwards) was significantly lower for patients on AFB (table 4).

There were no significant differences between the two groups in terms of their baseline and follow-up predialysis hemoglobin, total cholesterol, triglycerides, albumin, calcium, phosphate and bicarbonate, and dose of dialysis. Hemoglobin levels and spKt/V rose significantly in both groups $(\mathrm{p}<0.02)($ table 5$)$.

\section{Discussion}

The main finding of our randomized controlled trial is that AFB improves long- term cardiovascular stability during dialysis in comparison with conventional $\mathrm{BD}$, leading to a $40 \%$ reduction in the risk of IH (IRR 0.60 (95\% CI 0.53-0.68), $\mathrm{p}<0.0001)$. This effect of AFB was evident after the first 6 months of treatment (in agreement with the findings of previous short-term nonrandomized studies $[29,38])$ and persisted over the 36-month follow-up. 
The better intradialytic cardiovascular stability associated with AFB may conceivably be related to several factors: those peculiar to the hemodiafiltration techniques (which combine an enhanced removal of the higher molecular weight solutes with a more biocompatible system) [39]), though this may be questionable because the small substitution volume should only marginally affect middle molecule removal; the use of high-flux membrane (though in our study AFB coincided with a lower $\mathrm{IH}$ rate than $\mathrm{BD}$ regardless of membrane flux); the (albeit small) convective component (consistent with the results of a recent randomized controlled study [26] showing that online hemofiltration and hemodiafiltration reduce symptomatic $\mathrm{IH}$ in the long term); the absence of acetate in the bath and the infusate (since it has been demonstrated that even small amounts of this solute in the dialysate may impair cardiovascular reactivity [39]), and/or a thermal effect induced by the bicarbonate solution infused in the postdilution mode [39] since it is well known that a cold dialysate and/or infusate reduces the frequency of $\mathrm{IH}$ [40] (though this should not be a major contributor in our study since the infusate for AFB was usually warmed to a temperature similar to that of the dialysate and its infusion rate was always $<15 \%$ of the prescribed $\mathrm{Q}_{\mathrm{b}}$ ). Moreover, our study strongly suggests that the beneficial effects by AFB are unrelated to changes in intradialytic ultrafiltration and dry weight, since these parameters did not vary within or between the two groups.

The lower IH rate seen in our study with AFB was associated with a drop in predialysis SBP, similar to the situation seen with frequent HD [41] and unlike the one seen in online hemofiltration and hemodiafiltration [26], for which a lower rate of IH was associated with no change in predialysis SBP in the former and its increase in the latter (which could become clinically relevant in the long term [42]).

The two conditions may be related, since the reduction in IH may contribute to reducing the risk of long-term volume overload and interdialytic hypertension by lowering the need of intradialytic sodium loading and allowing a more consistent attainment of dry weight $[43,44]$. We also cannot exclude the possibility that a lag time phenomenon [45] (due to a more aggressive dehydration before randomization for AFB patients) contributing to different time course of predialysis SBP between BD and AFB; this is unlikely in our study, however, because the difference in SBP between BD and AFB only became evident as of the 12th month of follow-up (i.e. 20-22 months after starting dialysis), whereas the lag time phenomenon has been described only up to 10-12 months after attaining the target

AFB and Intradialytic Hypotension weight $[45,46]$. On the other hand, a lag time phenomenon may explain the time course of the changes in predialysis SBP for AFB versus BD, as a result of AFB being more successful in attaining a better extracellular volume control already in the first 6 months of this treatment.

We are aware that predialysis SBP is not the ideal way to assess blood pressure control and its prognostic value in HD patients [47] and it is probably just a marker of extracellular volume status [46], but the different blood pressure profile (and possibly volume status) in patients on $\mathrm{BD}$ and $\mathrm{AFB}$ may also contribute to the different trend in LVMI changes observed during the study, which were of potential clinical (though not statistical) significance, suggesting that AFB may also improve cardiovascular outcomes by preventing any gradual increase in LVMI, which proved to be a strong predictor of cardiovascular mortality in dialysis patients [48].

All the above findings suggest that patients who develop frequent $\mathrm{IH}$ when they start conventional $\mathrm{BD}$ (once their optimal dry weight has been identified) may be preferentially placed on AFB to minimize many dialysis-related cardiovascular adverse events.

In spite of its favorable effects, AFB did not influence the overall cardiovascular morbidity and mortality, possibly because our study recruited patients at much lower risk than we had originally expected, making it underpowered for the purpose of detecting any significant differences between the two treatment modalities due to the lower than expected cardiovascular event rate.

We confirmed that MCEs carry a high mortality among HD patients $[49,50]$ and showed that AFB reduces the risk of cardiovascular death for initial survivors of MCEs, indicating that this dialysis technique does not alter the severity of MCEs (or the efficacy of specific treatment for these conditions), but it can favorably affect the outcome of less severe, nonfatal MCE by comparison with standard $\mathrm{BD}$, possibly by reducing the burden of the repeatedly damaging ischemic effects of HD-related hypotension on the heart and the brain. Given the post hoc nature of our analysis however, these results should be considered only as food for thought and should be tested formally in further randomized clinical trials.

Moreover, any beneficial effect by AFB should be balanced against an increase in costs of dialysis. To give an example based on the Azienda Ospedaliera Universitaria Integrata Verona financial data system as at 2011, AFB is associated to an estimated extra cost for consumables of EUR 30-40 per session by comparison with BD.

We are aware that our study has several weaknesses. For a start, it was not blinded, since this would have been 
impossible in a clinical setting given the use of an infusate for AFB but not for BD. Secondly, our randomization was only partially successful, since the baseline IH rates in the AFB group were higher than in the BD group, meaning that our findings might have been prone to bias by regression to the mean. To take this bias into account, we performed a test of interaction by creating a baseline interaction variable, which proved not to be a significant determinant of IH rate during follow-up - unlike AFB. Thirdly, our findings are only applicable to patients on dialysis for a short time (8-10 months). Finally, our results may be biased by the fact that dry weight was assessed on clinical grounds (raising the possibility of the dialysis-related hypotensive episodes being difficult to separate from an inappropriate estimation of the target weight), the echocardiographic LVMI assessment was not performed at a centralized laboratory, and patients were recruited from many different centers and over a lengthy period of time; on the other hand, the impact of these confounders should be minimized by our study design enrolling both AFB and $\mathrm{BD}$ patients at any given center.

In conclusion, our randomized controlled trial shows that AFB lowers the long-term IH rate and the predialysis SBP by comparison with conventional BD. While AFB did not affect the incidence of cardiovascular events and deaths in our sample, it may reduce the cardiovascular mortality after a nonfatal major cardiac and cerebrovascular event, possibly thanks to the better intradialytic cardiovascular stability.

\section{Supplementary Appendix}

The following dialysis centers took part in the study: Czech Republic: Plzen; France: Fleury and Saint Brieuc. Germany: Augsburg, Bad Nauheim, Bad Windsheim Berlin, Chemnitz, Detmold, Donaueschingen, Dresden, Eisenhüttenstadt, Gelsenkirchen, Giessen, Göttingen; Herne, Magdeburg, Mannheim, Mühlhausen, Neuruppin, Plauen, Rostock, Schwandorf, Simmern, Tübingen, Unna, and Wiesbaden; Italy: Altamura, Arezzo, Ascoli Piceno/Pagliare, Bergamo, Bologna/Imola, Bolzano, Brescia/Montichiari, Cagliari, Cerignola, Chiari, Cinisello Balsamo, Como, Cremona, Crotone, Firenze, Gorizia, Ivrea, Lauria, Leno/Manerbio, Manduria, Martina Franca, Matera, Melegnano, Milano Policlinico, Milano Sacco, Milano San Carlo, Monza, Nuoro, Pesaro, Pontremoli, Ravenna, Rimini, Roma, Ruvo/Andria, San Giovanni Rotondo, San Miniato, San Severo, Scorrano/Corsano, Taranto, Torino Mauriziano, Trento, Treviso, Tricase, Trieste Cattinara, Verona Ospedale Civile Maggiore, Verona Borgo Roma, and Viterbo. Spain: Acoruna, Galdakao, Gandia, Leon, Madrid Del Aire, Madrid Maranon, Madrid La Paz, Ourense, Toledo, Valladolid RioOrtega, and Valladolid Hospital Universitario.

\section{Acknowledgments}

The dedication of the nephrologists and the staff at the participating Centers is gratefully acknowledged. Gambro-Hospal provided financial support.

\section{Disclosure Statement}

The authors have no conflicts of interest to disclose.

\section{References}

1 Foley RN, Parfrey PS, Harnett JD, Kent GM, Murray DC, Barre PE: Impact of hypertension on cardiomyopathy, morbidity and mortality in end-stage renal disease. Kidney Int 1996;49:1379-1385.

- 2 Tozawa M, Iseki K, Iseki C, Takishita S: Pulse pressure and risk of total mortality and cardiovascular events in patients on chronic hemodialysis. Kidney Int 2002;61:717-726.

-3 Cheung AK, Sarnak MJ, Yan G, Berkoben M, Heika R, Kaufman A, Lewis J, Rocco M, Toto $\mathrm{R}$, Windus D, Ornt D, Levey AS; HEMO Study Group: Cardiac diseases in maintenance hemodialysis patients: results of the HEMO study. Kidney Int 2004;65:2380-2389.

4 Charytan D, Kuntz RE, Mauri L, De Filippi C: Distribution of coronary artery disease and relation to mortality in asymptomatic hemodialysis patients. Am J Kidney Dis 2007;49: 409-416.
Harnet JD, Foley RN, Kent GR, Barre PE, Murray D, Parfreys PS: Congestive heart failure in dialysis patients: prevalence, incidence, prognosis and risk factors. Kidney Int 1995; 47:884-890.

6 6 London GM, Guerin AP, Marchais SJ, Pannier B, Safar ME, Day M, Metivier F: Cardiac and arterial interactions in end-stage renal disease. Kidney Int 1996;50:600-608.

7 Amann K, Ritz E: Microvascular disease - the Cinderella of uraemic heart disease. Nephrol Dial Transplant 2000;15:1493-1503.

8 Sigrist MK, McIntyre CW: Vascular calcification is associated with impaired microcirculatory function in chronic haemodialysis patients. Nephron Clin Pract 2008;108:c121c126.

9 Lindner A, Charra B, Sherrard DJ, Scribner BH: Accelerated atherosclerosis in prolonged maintenance hemodialysis. N Engl J Med 1974;290:697-701.
0 McIntyre CW: Effects of hemodialysis on cardiac function. Kidney Int 2009;76:371-375.

11 Davenport A, Cox C, Thuraisingham R: Achieving blood pressure targets during dialysis improve control but increases intradialytic hypotension. Kidney Int 2008;75:759-764.

12 McIntyre CW, Burton JO, Selby NM, Leccisotti L, Korsheed S, Baker CS, Camici PG: Hemodialysis-induced cardiac dysfunction is associated with an acute reduction in global and segmental myocardial blood flow. Clin J Am Soc Nephrol 2008;3:19-26.

13 Dasselaar JJ, Slart RHJA, Knip M, Pruim J, Tio RA, McIntyre CW, de Jong PE, Franssen CF: Hemodialysis is associated with a pronounced fall in myocardial perfusion. Nephrol Dial Transplant 2009;24:604-610.

14 Burton JO, Jefferies HJ, Selby NM, McIntyre CW: Hemodialysis-induced cardiac injury: determinants and associated outcomes. Clin J Am Soc Nephrol 2009;4:914-920. 
15 Koch M, Thomas B, Tschope W, Ritz E: Survival and predictors of death in dialyzed diabetic patients. Diabetologia 1993;36:11131117.

-16 Tisler A, Akocsi K, Borbas B, Fazakas L, Ferenczi S, Gorogh S, Culcsar I, Nagy L, Samik J, Szegedi J, Toth E, Wagner G, Kiss I: The effect of frequent or occasional dialysis-associated hypotension on survival of patients on maintenance haemodialysis. Nephrol Dial Transplant 2003;18:2601-2605.

-17 Shoji T, Tsubakihara Y, Fujii M, Imai E: Hemodialysis-associated hypotension as an independent risk factor for two-year mortality in hemodialysis patients. Kidney Int 2004;66: 1212-1220.

- 18 Bleyer AJ, Hartman J, Brannon PC, ReevesDaniel A, Satko SG, Russell G: Characteristics of sudden death in hemodialysis patients. Kidney Int 2006;69:2268-2273.

19 Barnes E, Dutka DP, Khan M, Camici PG, Hall RJ: Effects of repeated episodes of reversible myocardial ischemia on myocardial blood flow and function in humans. Am J Physiol Heart Circ Physiol 2002;282:H1603H1608.

-20 Wizemann V, Wabel P, Chamney P, Zaluska W, Moissl U, Rode C, Malecka-Masalska T, Marcelli D: The mortality risk of overhydration in haemodialysis patients. Nephrol Dial Transplant 2009;24:1574-1579.

21 McIntyre CW: Hemodialysis-induced myocardial stunning in chronic kidney disease - a new aspect of cardiovascular disease. Blood Purif 2010;29:105-110.

22 McIntyre CW: Recurrent circulatory stress: the dark side of dialysis. Semin Dial 2010;5: 449-451.

-23 Toyoda K, Fujii K, Fujimi S, Kumay J, Tsuchimochi $\mathrm{H}$, Ibayashi S, Iida M: Stroke in patients on maintenance hemodialysis: a 22year single-center study. Am J Kidney Dis 2005;45:1058-1066.

-24 Santoro A, Mancini E, Basile C, Amoroso L, Di Giulio S, Usberti M, Colasanti G, Verzetti G, Rocco A, Mimbasciati E, Panzetta G, Bolzani R, Grandi F, Polacchini M: Blood volume controlled hemodialysis in hypotension-prone patients: a randomized, multicenter controlled trial. Kidney Int 2002;62:1034-1045.

25 Locatelli F, Altieri P, Andrulli S, Bolasco P, Sau G, Pedrini LA, Basile C, David S, Feriani M, Montagna G, Di Iorio BM, Memoli B, Cravero R, Battaglia G, Zoccali C: Hemofiltration and hemodiafiltration reduce intradialytic hypotension in ESRD. J Am Soc Nephrol 2010;21:1798-1807.
26 Selby NM, Lambie SH, Camici PG, Baker CS, McIntyre CW: Occurrence of regional left ventricular dysfunction in patients undergoing standard and biofeedback dialysis. Am J Kidney Dis 2006;46:830-841.

27 Selby NM, Burton JO, Chesterton LJ, McIntyre CW: Dialysis-induced regional left ventricular dysfunction is ameliorated by cooling the dialysate. Clin J Am Soc Nephrol 2006;1:1216-1225.

28 Zucchelli P, Santoro A, Raggiotto G: Biofiltration in uremia: preliminary observations. Blood Purif 1984;2:187-195.

29 Santoro A, Guarnieri F, Ferramosca E, Grandi F: Acetate-free biofiltration; in Ronco C, Canaud P, Aljiama P (eds): Contributions to Nephrology. Basel, Karger, 2007, vol 158, pp 138-152.

30 Rabindranath KS, Strippoli GE, Roderick P, Wallace SA, MacLeod AM, Daly C: Comparison of hemodialysis, hemofiltration, and acetate-free biofiltration for ESDR: systematic review. Am J Kidney Dis 2005;45:437-447.

31 Santoro A, Panzetta G, Tessitore N, Atti M, Mancini E, Esteban J, London G, Martinez Ara J, Miguel JL, Neumann KH, Opatrny K, Perez R, Perrone B, Wizemann V, Zucchelli P: A prospective randomized European multicentre study of medium-long run mortality and morbidity comparing acetate-free biofiltration and bicarbonate dialysis. J Nephrol 1999; 12:375-382.

-32 Charlson ME, Pompei P, Ales KL, MacKenzie CR: A new method of classifying prognostic comorbidity in longitudinal studies: development and validation. J Chronic Dis 1987;40: 373-383.

33 Daugirdas JT: Second-generation logarithmic estimates of single-pool variable volume $\mathrm{Kt} / \mathrm{V}$ : an analysis of error. J Am Soc Nephrol 1993;4:1205-1213.

34 Devereux RB, Alonso DR, Lutas EM, Gottlieb GJ, Campo E, Sachs I, Reichek N: Echocardiographic assessment of left ventricular hypertrophy: comparison to necropsy findings. Am J Cardiol 1986;57:450-458.

- 35 Ergin A, Muntner P, Sherwin R, He J: Secular trends in cardiovascular disease mortality, incidence, and case fatality rates in adults in the United States. Am J Med 2004;117:219-227.

36 Sedwick P: Incidence rate ratio. BMJ 2010; 341:c4804.

37 Aiken LS, West SG: Multiple Regression: Testing and Interpreting Interactions. Thousand Oaks, Sage Publication Inc, 1991, pp 116-137.

38 Schrander-van der Meer AM, ter Wee PM, Kan G, Donker AJ, van Dorp WT: Improved cardiovascular variables during acetate-free biofiltration. Clin Nephrol 1999;51:304-309.
39 Cavalcanti S, Cianfrini A, Severi F, Badiali F, Bini S, Gattiani A, Cagnoli L, Santoro A: Model-based study on the effect of hemodialysis technique on the compensatory response to hypovolemia. Kidney Int 2004;65:1499-1510.

40 Selby NM, McIntyre CW: A systematic review of the clinical effects of reducing dialysate fluid temperature. Nephrol Dial Transplant 2006;21:1883-1189.

41 FHN Trial Group: In-center hemodialysis six times per week versus three times per week. N Engl J Med 2010;363:2287-2300.

42 Stidley CA, Hunt WC, Tentori F, Rohrscheib MR, Bedrick EJ, Meyer KB, Johnson HK, Zager PG: Changing relationship of blood pressure with mortality over time among hemodialysis patients. J Am Soc Nephrol 2006;17: 513-520.

43 Agarwal R, Weir MR: Dry-weight: a concept revisited in an effort to avoid medication-directed approaches for blood pressure control in hemodialysis patients. Clin J Am Soc Nephrol 2010;5:1255-1260.

44 Landry DW, Oliver JA: Blood pressure instability during hemodialysis. Kidney Int 2006; 69:1710-1711.

45 Chazot C, Vo-Van C, Deleaval P, Lorriaux C, Hurot JM, Mayor B, Jean G: Predialysis systolic blood pressure evolution in incident hemodialysis patients: effect of the dry weight method and prognostic value. Blood Purif 2012;33:275-283.

46 Chazot C, Charra B, Vo Van C, Jean G, Vanel T, Calemard E, Terrat JC, Ruffet M, Laurent G: The Janus-faced aspect of 'dry weight'. Nephrol Dial Transplant 1999;14:121-124.

-47 Agarwal R, Andersen MJ, Bishu K, Saha C: Home blood pressure monitoring improves the diagnosis of hypertension in hemodialysis patients. Kidney Int 2006;69:900-906.

$\checkmark 48$ Zoccali C, Benedetto FA, Mallamaci F, Tripepi G, Giacone G, Stancanelli B, Cataliotti A, Malatino LS: Left ventricular mass monitoring in the follow-up of dialysis patients: prognostic value of left ventricular hypertrophy progression. Kidney Int 2004;65:1492-1498.

49 Herzog CA, Ma JZ, Collins AJ: Poor longterm survival after acute myocardial infarction among patients on long-term dialysis. $\mathrm{N}$ Engl J Med 1998;339:799-805.

50 Iseki K, Fukiyama K; Okawa Dialysis Study (OKIDS) Group: Clinical demographics and long-term prognosis after stroke in patients on chronic hemodialysis Nephrol Dial Transplant 2000;15:1808-1813. 